\title{
Growth of iron nitride thin films by molecular beam epitaxy
}

\author{
Michio Naito ${ }^{1}$, Koji Uehara ${ }^{1}$, Rikimaru Takeda ${ }^{1}$, \\ Yoshitaka Taniyasu $^{2}$, and Hideki Yamamoto ${ }^{2}$ \\ ${ }^{1}$ Department of Applied Physics, Tokyo University of Agriculture and Technology, Koganei, \\ Tokyo 184-8588, Japan \\ 2 NTT Basic Research Laboratories, NTT Corporation, 3-1 Morinosato-Wakamiya, Atsugi, \\ Kanagawa 243-0198, Japan
}

\begin{abstract}
-
Iron nitride films were grown by atomic-nitrogen-assisted molecular beam epitaxy. ZnS-type FeN ( $\gamma$ '-FeN) was synthesized with low Fe evaporation rates $(\leq 0.2 \AA / \mathrm{s})$ at low growth temperatures below $210^{\circ} \mathrm{C}$ whereas $\gamma^{\prime}-\mathrm{Fe}_{4} \mathrm{~N}$ was synthesized with high $\mathrm{Fe}$ evaporation rates $(\geq 1.0 \AA / \mathrm{s})$ at $130-415^{\circ} \mathrm{C}$. Our results indicate that the stabilization of ZnS-type FeN requires not only the fulfillment of thermodynamic constraints but also the control of a delicate balance of kinetically driven competition. The use of lattice-matched $\mathrm{GaN}(0001)$ substrates enables the growth of epitaxial films of ZnS-type FeN.
\end{abstract}

Key words:

A1. Crystal structure, A3. Molecular beam epitaxy, B1. Nitrides, B2. Magnetic materials

Corresponding author:

Michio Naito, Department of Applied Physics, Tokyo University of Agriculture and Technology, Naka-cho 2-24-16, Koganei, Tokyo 184-8588, Japan.

Tel. +81 42388 7229; fax: +81 42385 6255. E-mail address: minaito@cc.tuat.ac.jp. 


\section{INTRODUCTION}

It is known that a wide variety of compounds exist in the binary Fe-N system: e.g., $\alpha "-\mathrm{Fe}_{16} \mathrm{~N}_{2}, \alpha$ '- $\mathrm{Fe}_{8} \mathrm{~N}, \gamma^{\prime}-\mathrm{Fe}_{4} \mathrm{~N}, \varepsilon-\mathrm{Fe}_{3} \mathrm{~N}, \zeta-\mathrm{Fe}_{2} \mathrm{~N}$, and $\gamma$ '-FeN [1]. Some of the Fe-rich phases $\left(\alpha{ }^{\prime}-\mathrm{Fe}_{16} \mathrm{~N}_{2}, \gamma^{\prime}-\mathrm{Fe}_{4} \mathrm{~N}\right)$ are attractive for their high magnetic moment [2]. Increasing the $\mathrm{N} / \mathrm{Fe}$ ratio decreases the magnetic moment rapidly, which makes the compounds less interesting from a magnetic application point of view. Furthermore the difficulty in the synthesis of Fe-N increases markedly for the more N-rich phase. Accordingly, the N-rich region $(\mathrm{N} / \mathrm{Fe} \sim$ 1) in the Fe-N binary phase diagram was almost unexplored until the early 1990's. Indeed no bulk synthesis of FeN has yet been reported. The synthesis of FeN has so far relied on thin-film growth techniques such as sputtering [4-6], pulsed laser deposition [7], laser-nitriding [8], molecular beam epitaxy assisted by atomic nitrogen [8-10], etc.

Many transition-metal nitrides with the $1: 1$ stoichiometry adopt the $\mathrm{NaCl}$ structure, apart from small deviations from the ideal geometry such as small tetragonal distortions and such-like. In fact, the early members of $3 d$ transition-metal nitrides, $\mathrm{ScN}$ to $\mathrm{MnN}$, adopt the $\mathrm{NaCl}$ structure, and some ( $\mathrm{TiN}, \mathrm{VN})$ are superconducting. In contrast, $\mathrm{FeN}$ and $\mathrm{CoN}$ both crystallize in the zinc-blend $(\mathrm{ZnS})$ structure. The subsequent members, $\mathrm{NiN}$ and $\mathrm{CuN}$, are theoretically predicted to adopt the $\mathrm{ZnS}$ structure although they have not hitherto been synthesized. The transition-metal nitrides possess a richness of structural and electric/magnetic properties and form an interesting family of compounds [11].

In early efforts, there have been reports of the existence of two compounds (two structural isomers) with an FeN stoichiometry: nonmagnetic $\gamma$ "-FeN with the $\mathrm{ZnS}$ structure and probably antiferromagnetic $\gamma$ '"'-FeN with the $\mathrm{NaCl}$ structure. In $\mathrm{ZnS}$-type $\gamma$ "'-FeN, each nitrogen atom is coordinated by four iron atoms at the corners of a regular tetrahedron whereas in NaCl-type $\gamma$ "'-FeN, each nitrogen atom is coordinated by six iron atoms at the corners of a regular octahedron. The latter coordination is commonly seen in the Fe-N system $\left(\alpha{ }^{\prime}-\mathrm{Fe}_{16} \mathrm{~N}_{2}, \alpha^{\prime}-\mathrm{Fe}_{8} \mathrm{~N}, \gamma^{\prime}-\mathrm{Fe}_{4} \mathrm{~N}, \varepsilon-\mathrm{Fe}_{3} \mathrm{~N}\right.$, and $\left.\zeta-\mathrm{Fe}_{2} \mathrm{~N}\right)$. Hinomaru et al. carried out 
${ }^{57} \mathrm{Fe}$ Mössbauer spectroscopy measurements for the films prepared by sputtering. They claimed that stoichiometric $\operatorname{FeN}_{x}(x \approx 1.0)$ formed in the $\mathrm{ZnS}$ phase whereas nitrogen-deficient $\mathrm{FeN}_{x}(x \approx 0.6)$ was a mixture of two phases having the $\mathrm{ZnS}$ and $\mathrm{NaCl}$ structures [12]. Later, however, Andrzejewsak et al. prepared the specimens by MBE and identified the structure of $\mathrm{FeN}_{x}(x>0.5)$ as the $\mathrm{ZnS}$ structure with nitrogen vacancies [8]. This conclusion was reached by conversion electron Mössbauer spectroscopy. Furthermore, developments in MBE techniques have enabled the growth of single-crystalline single-phase films having the $\mathrm{ZnS}$ structure [9, 10], while the existence of the NaCl-type FeN remains elusive.

In this article, we report the influence of growth parameters on the resultant phase formation in the Fe-N films prepared by atomic-nitrogen-assisted MBE. We found that not only the growth temperature (thermodynamic parameter) but also the growth rate (kinetic parameter) are critical in stabilizing ZnS-type FeN. We also report the transport properties of FeN films, on which only very limited information has been available. The resistivity of ZnS-type FeN films shows a metallic but complicated temperature dependence, which suggests the possible existence of some phase transition.

\section{Experimental}

Fe nitride films were grown in the customer-designed ultrahigh vacuum (UHV) MBE system with base pressure of $\sim 1 \times 10^{-9}$ Torr. Fe was evaporated from an e-beam source, while simultaneously exposing a substrate to a flux of atomic nitrogen generated by a radio-frequency (RF) plasma discharge source (ARIOS, IRFS-504). The atomic nitrogen source was operated with the input RF power of $200 \sim 400 \mathrm{~W}$ and $\mathrm{N}_{2}$ flow rate of $0.7 \mathrm{sccm}$. The growth temperature $\left(T_{\mathrm{s}}\right)$ was varied from ambient to $500^{\circ} \mathrm{C}$. It turned out that the evaporation rate of $\mathrm{Fe}\left(R_{\mathrm{Fe}}\right)$ is a critical parameter deciding which phase forms, therefore the rate was varied in a fairly wide range from 0.05 to $1.0 \AA / \mathrm{s}$. The film thickness is estimated 
from the Fe deposition rate, assuming the sticking coefficient of $\mathrm{Fe}$ is 1.0, which may be reasonable at growth temperatures below $500^{\circ} \mathrm{C}$.

The substrates used were mainly $\mathrm{GaN}(0001)$ and $\mathrm{MgO}(001)$. $\mathrm{GaN}(0001)$ was grown on sapphire(0001) by metalorganic vapor phase epitaxy (MOVPE) using the AlON buffer-layer technology [13]. GaN has the wurtzite structure (hexagonal) with the lattice constants of $a_{0}=3.189 \AA$ and $c_{0}=5.185 \AA$. The Ga-Ga distance is $3.189 \AA$, which is close to the Fe-Fe distance $(3.046 \AA)$ in ZnS-type $\gamma$ "-FeN $\left(a_{0}=4.307 \AA\right)$. On GaN(0001), the epitaxial growth of $\gamma^{\prime \prime}-\mathrm{FeN}(111)$ films is expected. On the other hand, $\mathrm{MgO}$ has the $\mathrm{NaCl}$ structure with $a_{0}=4.211 \AA$, which is close to $a_{0}=4.307 \AA$ of FeN. On $\mathrm{MgO}(001)$, the epitaxial growth of $\gamma$ '-FeN(001) films is expected (cube-on-cube epitaxial relationship). Our preliminary experiments for the growth of elemental iron films on oxide substrates indicated that reaction takes place between iron and oxygen in the substrates at $T_{\mathrm{s}}$ above $350^{\circ} \mathrm{C}$. Nitriding of surfaces of oxide substrates before growth appears to suppress this reaction, at least, partially. The structure of the films was characterized by in-situ reflection high-energy electron diffraction (RHEED) and X-ray diffraction (XRD). The $\omega-2 \theta$ (equivalently $\theta-2 \theta$ ) XRD scans were performed using Rigaku, Smart Lab with $\mathrm{Cu} \mathrm{K}_{\alpha}$ radiation, which is monochromatized by $\mathrm{Ge}(220)$ crystals. The resistivity-vs-temperature $(\rho-T)$ characteristics of the films were measured by a standard four-probe method.

\section{Results and Discussion}

\section{3-1. Low Fe evaporation rate}

First we describe the results of the growth with low Fe evaporation rates $\left(R_{\mathrm{Fe}}=\right.$ $0.05 \sim 0.2 \AA / \mathrm{s}$ ). Figure 1 (a) shows the XRD patterns of the Fe-N films grown with $R_{\mathrm{Fe}}=0.1$ $\AA / \mathrm{s}$ for $30 \mathrm{~min}$ on $\mathrm{GaN}(0001)$ at different growth temperatures from ambient to $250^{\circ} \mathrm{C}$. The thickness estimated is $305 \AA$. The input power for the RF atomic nitrogen source was optimized and set to $300 \mathrm{~W}$. The (111) and (222) reflections from ZnS-type $\gamma$ '-FeN are 
observed with no impurity peak in the films grown at $T_{\mathrm{s}}$ from 90 to $210^{\circ} \mathrm{C}$ whereas almost no peak is observed in the film grown at $T_{\mathrm{s}}=250^{\circ} \mathrm{C}$. The result indicates that the single-phase $\mathrm{FeN}(111)$ films with the $\mathrm{ZnS}$ structure are grown on $\mathrm{GaN}(0001)$ at $T_{\mathrm{s}}$ from 90 to $210^{\circ} \mathrm{C}$. For comparison, the XRD patterns of the Fe-N films grown on $\mathrm{MgO}(001)$ are shown in Fig. 1(b). The films are crystallized in the $\mathrm{ZnS}$ structure in the range of $T_{\mathrm{s}}$ from 130 to $210^{\circ} \mathrm{C}$ and in $\zeta-\mathrm{Fe}_{2} \mathrm{~N}$ at $T_{\mathrm{s}}=250^{\circ} \mathrm{C}$. As mentioned in $\S 2$, the cube-on-cube epitaxial relationship is expected for $\mathrm{ZnS}$-type $\mathrm{FeN}$ films on $\mathrm{MgO}$. Against this expectation, the films on $\mathrm{MgO}$ are a mixture of $\mathrm{FeN}(001)$ and $\mathrm{FeN}(111)$ grains. At a first look, only the (111) and tiny (222) reflections appear to be present in the XRD patterns (Fig. 1(b)). However, the enlarged view of the XRD pattern near $\theta \approx 40^{\circ}$ (Fig. 1(c)) clearly reveals the presence of the (002) reflection of $\mathrm{FeN}$ in the tail of the intense (002) reflection of an $\mathrm{MgO}$ substrate. The observed (integrated) intensity ratio of (002) : (111) is about $1: 1$ for the film grown at $T_{\mathrm{s}}=170^{\circ} \mathrm{C}$. According to the experimental powder XRD pattern of FeN by Suzuki et al. [4], the intensity ratio, (002) : (111), is $29: 100$. By correcting the observed intensities of the (002) and (111) reflections by this ratio, the volume ratio of the (001) oriented portion to (111) oriented one in the films is 3 4. Namely, the films grown on $\mathrm{MgO}(001)$ are dominantly $\mathrm{FeN}(001)$ but with a certain amount of $\mathrm{FeN}(111)$.

In Fig. 2(a) and 2(b), the peak intensity and the $d$ value of the (111) reflection of the ZnS-type FeN films on both of $\mathrm{GaN}$ and $\mathrm{MgO}$ are plotted against $T_{\mathrm{s}}$. The former indicates that the optimum growth temperature for $\mathrm{ZnS}$-type $\mathrm{FeN}$ is $130-170^{\circ} \mathrm{C}$. With regard to the latter, the $d$ value is slightly smaller in the films on $\mathrm{GaN}$ than on $\mathrm{MgO}$. This may be explained by epitaxial strain. It has been reported [10] that FeN thin films $(\sim 150 \AA)$ on GaN are distorted by in-plane tensile epitaxial strain (3.189 $\AA$ for the Ga-Ga distance versus 3.046 $\AA$ for the Fe-Fe distance) and that, accordingly, the out-of-plane lattice constant becomes shorter than the value reported for thick FeN films prepared by sputtering [4]. On the other hand, the lattice constant of the films on $\mathrm{MgO}$ is close to the reported value, indicating that 
the strain is mostly relaxed [footnote\#1].

Figure 3 shows the corresponding $\rho-T$ data of these films. Only the $\rho-T$ curves of the films on GaN are plotted since the behavior is essentially identical for films on two substrates. The films grown at $T_{\mathrm{s}}$ from 130 to $170^{\circ} \mathrm{C}$ have the lowest resistivity. The $\rho-T$ curve is concave at $T>\sim 150 \mathrm{~K}$ and convex at $T<\sim 150 \mathrm{~K}$ with an inflection point at $\sim 150 \mathrm{~K}$. This inflection point may suggest the existence of some phase transition. Figure 2(c) and 2(d) are a summary of the $\rho-T$ data: (c) $\rho(300 \mathrm{~K})$ and (d) residual resistivity ratio (RRR) plotted as a function of $T_{\mathrm{s}}$. The RRR is defined as $\rho(300 \mathrm{~K}) / \rho(4.2 \mathrm{~K})$ and a measure of metallicity. The $\rho(300 \mathrm{~K})$ is the lowest and the RRR is the largest in the same range of $T_{\mathrm{s}}$ as the crystallinity is the highest (Fig. 2(a)). The trend implies that higher crystallinity provides more metallic films.

As mentioned before, the evaporation rate of $\mathrm{Fe}$ is a critical parameter for stabilizing the $\mathrm{ZnS}$ phase of FeN. Figure 4 shows the XRD patterns of the films grown on $\mathrm{MgO}$ at $T_{\mathrm{s}}=$ $170^{\circ} \mathrm{C}$ with different $R_{\mathrm{Fe}}$ from 0.05 to $1.0 \AA / \mathrm{s}$. The deposition time is $30 \mathrm{~min}$ for $R_{\mathrm{Fe}}=$ 0.05-0.2 $\AA / \mathrm{s}, 15 \mathrm{~min}$ for $0.4 \AA / \mathrm{s}$, and $5 \mathrm{~min}$ for $1.0 \AA / \mathrm{s}$ [footnote\#2]. As seen in this figure, the $\mathrm{ZnS}$ phase forms for $R_{\mathrm{Fe}}=0.05 \sim 0.2 \AA / \mathrm{s}$ whereas the $\gamma^{\prime}-\mathrm{Fe}_{4} \mathrm{~N}$ forms for $R_{\mathrm{Fe}}=1.0$ $\AA /$ s. The film grown with $R_{\mathrm{Fe}}=0.4 \AA / \mathrm{s}$ showed no XRD peak. The result indicates that low growth rate is prerequisite for stabilizing $\mathrm{ZnS}$-type FeN.

\section{3-2. High Fe evaporation rate}

Next we describe the results of the growth with a high Fe evaporation rate $\left(R_{\mathrm{Fe}}=1.0\right.$ $\AA / \mathrm{s})$. Figure 5(a) shows the XRD patterns of the Fe-N films grown for 5 min on $\mathrm{MgO}(001)$ at different growth temperatures from ambient to $500^{\circ} \mathrm{C}$. The thickness estimated is $464 \AA$. The films are crystallized in $\gamma^{\prime}-\mathrm{Fe}_{4} \mathrm{~N}$ with the (001) plane parallel to the substrate surface at $T_{\mathrm{s}}$ from 130 to $415^{\circ} \mathrm{C}$, and show sharper and stronger XRD peaks for higher $T_{\mathrm{s}}$. The films grown at $T_{\mathrm{s}}$ below $130^{\circ} \mathrm{C}$ show no XRD peak whereas the film grown at $T_{\mathrm{s}}=500^{\circ} \mathrm{C}$ is 
elemental $\mathrm{Fe}$ containing no nitrogen, indicating that $\gamma^{\prime}-\mathrm{Fe}_{4} \mathrm{~N}$ is not stable at $T_{\mathrm{s}}=500^{\circ} \mathrm{C}[14]$. It should be emphasized again that ZnS-type FeN has never formed with high $R_{\mathrm{Fe}}(\geq 1.0 \AA / \mathrm{s})$ even by lowering $T_{\mathrm{s}}$ down to $30^{\circ} \mathrm{C}$, judging from both of the XRD patterns and $\rho-T$ curves. Instead some reflections from hexagonal $\varepsilon-\mathrm{Fe}_{3} \mathrm{~N}\left(a_{0}=4.7080 \AA, c_{0}=4.3885 \AA\right.$, see Fig. 5(c), [15]) was discernible by lowering $T_{\mathrm{s}}$, although the intensity was small, in the films grown on substrates such as $\mathrm{LaAlO}_{3}(001), \mathrm{YAlO}_{3}(001)$, etc. other than $\mathrm{MgO}$ [footnote\#3].

The crystal structure of $\gamma^{\prime}-\mathrm{Fe}_{4} \mathrm{~N}$ is cubic and can be viewed as the face-centered cubic (fcc) lattice of Fe with interstitial $\mathrm{N}$ at the body-center position (see Fig. 5(c)). This is the simplest structure among the Fe-N binary system. The lattice constant, $a_{0}=3.795 \AA$, of $\gamma^{\prime}-\mathrm{Fe}_{4} \mathrm{~N}$ should be compared with $3.45 \AA$ for fcc $\gamma$-Fe, which is an unstable phase at ambient temperature (the stable phase at ambient temperature is bcc $\alpha$-Fe with $a_{0}=2.87 \AA$ ). Interstitial nitrogen in $\gamma^{\prime}-\mathrm{Fe}_{4} \mathrm{~N}$ expands the fcc lattice by $10 \%$ in $a_{0}$ and reduces the $3 d-3 d$ overlap, thereby stabilizing a ferromagnetic state with a Curie temperature of $767 \mathrm{~K}$. This is one of the reasons why iron and nitrogen look like a promising combination for magnetic applications [1].

Figure 5(b) shows the corresponding $\rho-T$ data of these films. The $\rho-T$ curves of $\gamma^{\prime}-\mathrm{Fe}_{4} \mathrm{~N}$ films have prominent convex curvature. Figure 6 is a summary of the results: (a) intensity of the (002) reflection, (b) $d$ value of the (002) reflection, (c) $\rho(300 \mathrm{~K})$, and (d) RRR. The best crystallinity of films was attained at $T_{\mathrm{s}}=415^{\circ} \mathrm{C}$, which is just below the decomposition temperature $\left(\leq 500^{\circ} \mathrm{C}\right)$. This trend in the growth of $\mathrm{Fe}_{4} \mathrm{~N}$ films appears to correspond to the Hammond-Bormann law in the growth of oxide films, which claims that proximity to the equilibrium decomposition line may be favorable for in-situ film growth [16]. At $T_{\mathrm{s}}=415^{\circ} \mathrm{C}$, the electrical conductivity is also optimized. The RRR value reaches 33, which is substantially higher than $\sim 10$ for epitaxial films grown by dc reactive sputtering [17] or $\sim 3$ for polycrystalline films grown by dc reactive facing-target sputtering [18]. The high RRR value, namely low residual resistivity of the $\mathrm{Fe}_{4} \mathrm{~N}$ films grown by reactive coevaporation 
implies high crystallinity and/or low density of defects such as nitrogen vacancies.

\section{Summary}

High-quality thin films of ZnS-type $\mathrm{FeN}\left(\gamma^{\prime \prime}-\mathrm{FeN}\right)$ and $\gamma^{\prime}-\mathrm{Fe}_{4} \mathrm{~N}$ were grown by atomic-nitrogen-assisted MBE. It requires not only low temperatures (below $170^{\circ} \mathrm{C}$ ) but also low Fe evaporation rates $(\leq 0.2 \AA / \mathrm{s})$ to stabilize the $\mathrm{ZnS}$ phase of FeN. This indicates that thermodynamics as well as kinetics are critical for stabilizing ZnS-type FeN. Our finding may provide a clue for the synthesis of $\mathrm{NiN}$ and $\mathrm{CuN}$, which are yet to be synthesized. The optimum growth temperature for $\gamma^{\prime \prime}-\mathrm{FeN}$ is $130-170^{\circ} \mathrm{C}$. FeN films grow on $\mathrm{GaN}(0001)$ with $\mathrm{FeN}(111) / / \mathrm{GaN}(0001)$ whereas they grow on $\mathrm{MgO}(001)$ with $\mathrm{FeN}(001) / / \mathrm{MgO}(001)$ as the major orientation but with $\mathrm{FeN}(111) / \mathrm{MgO}(001)$ as the minor orientation. High $\mathrm{Fe}$ evaporation rates $(1 \AA / \mathrm{s})$ stabilizes $\gamma^{\prime}-\mathrm{Fe}_{4} \mathrm{~N}$. The optimum growth temperature for $\gamma^{\prime}-\mathrm{Fe}_{4} \mathrm{~N}$ is $415^{\circ} \mathrm{C}$, at which a RRR value as high as 33 was obtained.

\section{Acknowledgement}

The work was partly supported by Advanced Low Carbon Technology (ALCA), Japan Science and Technology Agency.

\section{Footnote}

[\#1] In Fig. 2(b), only the $d(111)$ values from the (111) reflection of the films are included. The $d$ value evaluated from the (002) reflection, although not very accurate due to the severe interference by the intense substrate reflection, is $2.151 \AA$, which is also in a good agreement with the reported value $\left(a_{0} / 2=2.1535\right)[4]$.

[\#2] The thickness of the film grown with each $R_{\mathrm{Fe}}$ is different: 153, 306, 612, 612, and $510 \AA$ for the deposition with $R_{\mathrm{Fe}}=0.05,0.1,0.2,0.4$, and $1.0 \AA / \mathrm{s}$, respectively.

[\#3] The $(11 \underline{2} 1)$ reflection $\left(2 \theta=43.7^{\circ}\right)$ of hexagonal $\varepsilon-\mathrm{Fe}_{3} \mathrm{~N}$ was observed on cubic 
$\mathrm{LaAlO}_{3}, \mathrm{YAlO}_{3}$, and $\mathrm{SrTiO}_{3}$ substrates. In the case of the films on $\mathrm{MgO}$, the (112 1$)$ reflection from $\varepsilon-\mathrm{Fe}_{3} \mathrm{~N}$ may be buried in the tail of a huge substrate (002) peak. 


\section{References}

[1] J. M. D. Coey and P. A. I. Smith, J. Magn. Magn. Mater. 200 (1999) 405-424.

[2] T. K. Kim and M. Takahashi, Appl. Phys. Lett. 20 (1972) 492-494.

[3] N. Heiman and N. S. Kazama, J. Appl. Phys. 52 (1981) 3562-3564.

[4] K. Suzuki, H. Morita, T. Kaneko, H. Yoshida, and H. Fujimori, J. Alloys Compounds 201 (1993) 11-16.

[5] L. Rissanen, M. Neubauer, K. P. Lieb, P. Schaaf, J. Alloys Compounds 274 (1998) $74-82$.

[6] L. Rissanen, P. Schaaf, M. Neubauer, K. P. Lieb, J. Keinonen, and T. Sajavaara, Appl. Surf. Sci. 138-139 (1999) 261-265.

[7] M. Gupta, A. Gupta, P. Bhattacharya, P. Misra, L. M. Kukreja, J. Alloys Compounds 326 (2001) 265-269.

[8] E. Andrzejewska, R. Gpnzalez-Arrabal, D. Borsa,, D. O. Boerma, Nucl. Instr. Meth. Phys. Res. B 249 (2006) 838-842.

[9] C. Navio, J. Alvarez, M. J. Capitan, F. Yndurain, and R. Miranda, Phys. Rev. B 78 (2008) 155417.

[10] W. Lin, J. Pak, D. C. Ingram, and A. R. Smith, J. Alloys Compounds 463 (2008) 257-262.

[11] R. Dronskowski, “Computational Chemistry of Solid State Materials”, (Wiley-VCH Verlag GmbH \&Co. KGaA, Weinheim, 2005) §3.2.

[12] T. Hinomura and S. Nasu, Hyperfine Interact. 111 (1998) 221-226.

[13] K. Kumakura and T. Makimoto, J. Cryst. Growth 292 (2006) 155-158.

[14] F. Tessier, A. Navrotsky, R. Niewa, A. Leineweber, H. Jacobs, S. Kikkawa, M. Takahashi, F. Kanamaru, and F. J. DiSalvo, Solid State Sci. 2 (2000) 457-462.

[15] H. Jacobs, D. Rechenbach, and U. Zachwieja, J. Alloys Compounds 227 (1995) $10-17$. 
[16] R. H. Hammond and R. Bormann, Physica C 162-164 (1989) 703-704.

[17] M. Tsunoda, Y. Komasaki, S. Kokadao, S. Isogami, C-C. Chen, and M. Takahashi, Appl. Phys. Express 2 (2009) 083001.

[18] W. B. Mi, X. P. Feng, X. F. Duan, H. Yang, Y. Li, and H. L. Bai, Thin Solid Films 520 (2012) 7035-7040. 


\section{Figure captions}

Figure 1. XRD patterns of the Fe-N films grown with $R_{\mathrm{Fe}}=0.1 \AA / \mathrm{s}$ on (a) GaN(0001) and (b) $\mathrm{MgO}$ substrates at different $T_{\mathrm{s}}$. The enlarged view near $\theta \approx 40^{\circ}$ for the film grown at $T_{\mathrm{s}}=$ $170^{\circ} \mathrm{C}$ in (b) is shown in (c), which clearly reveals the presence of the (002) reflection of FeN. The component of the (002) reflection of FeN was extracted as shown in (c), which was performed by subtracting a Lorentzian fit (broken line) for the tail of the (002) reflection of $\mathrm{MgO}$ from the experimental curve.

Figure 2. Summary of the structural and transport properties of the Fe-N films grown with $R_{\mathrm{Fe}}$ $=0.1 \AA / \mathrm{s}$ on $\mathrm{GaN}(0001)$ (solid circles) and $\mathrm{MgO}(001)$ (crosses) as a function of $T_{\mathrm{s}}$ : (a) intensity of the (111) reflection, (b) $d$ value of the (111) reflection, (c) $\rho(300 \mathrm{~K})$, and (d) RRR. The dash-and-dot line in (b) represents the $d$ value for the thick films prepared by sputtering in ref. 4.

Figure 3. Resistivity versus temperature for the Fe-N films grown with $R_{\mathrm{Fe}}=0.1 \AA$ s on $\mathrm{GaN}(0001)$ at different $T_{\mathrm{s}}$.

Figure 4. XRD patterns of the of the Fe-N films grown on $\mathrm{MgO}(0001)$ substrates at $T_{\mathrm{s}}=$ $170^{\circ} \mathrm{C}$ with different $R_{\mathrm{Fe}}$.

Figure 5. (a) XRD patterns and (b) $\rho-T$ curves of the of the Fe-N films grown with $R_{\mathrm{Fe}}=1.0$ $\AA / \mathrm{s}$ on $\mathrm{MgO}(001)$ substrates at different $T_{\mathrm{s}}$. The crystal structures of typical compounds in the Fe-N system are illustrated in (c).

Figure 6. Summary of the structural and transport properties of the Fe-N films grown with $R_{\mathrm{Fe}}$ $=1.0 \AA / \mathrm{s}$ on $\mathrm{MgO}(001)$ as a function of $T_{\mathrm{s}}$ : (a) intensity of the (002) reflection, (b) $d$ value of 
the (002) reflection, (c) $\rho(300 \mathrm{~K})$, and (d) RRR. The dash-and-dot line in (b) represents the $d$ value for bulk samples of $\gamma^{\prime}-\mathrm{Fe}_{4} \mathrm{~N}$. The data points indicated by $(\mathbf{O})$ are for the films decomposed to elemental Fe. The gray line indicates the optimum growth temperature for $\gamma^{\prime}-\mathrm{Fe}_{4} \mathrm{~N}$. 


\section{Figure 1}

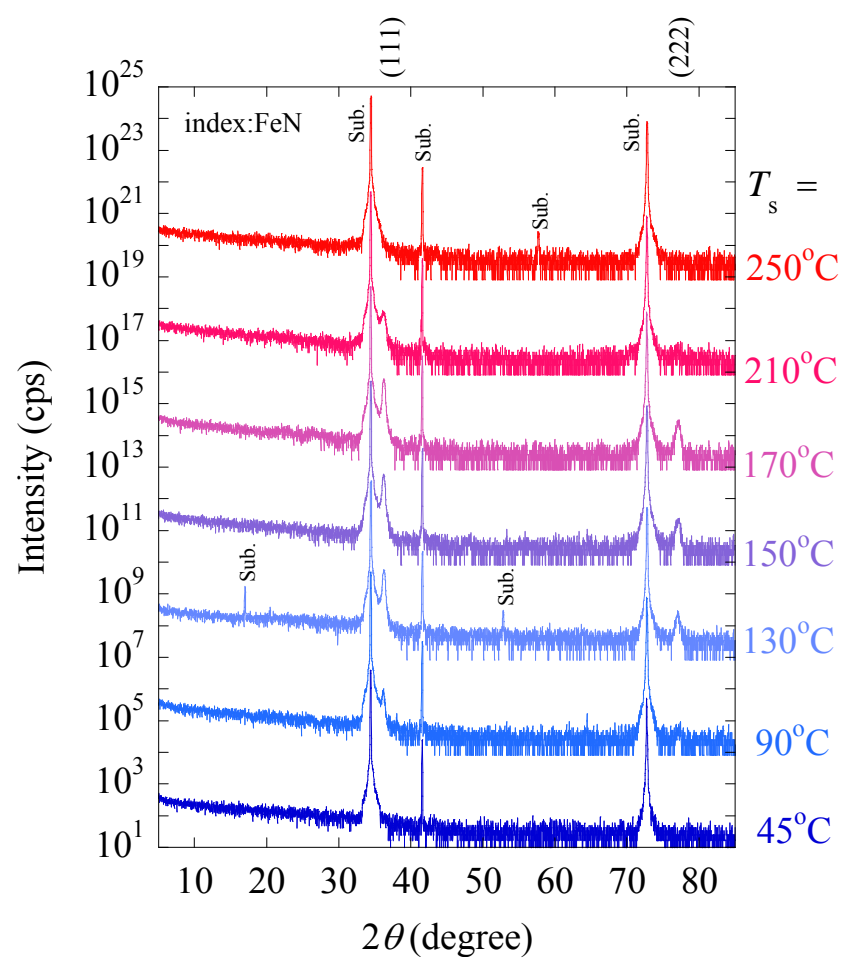

(a)

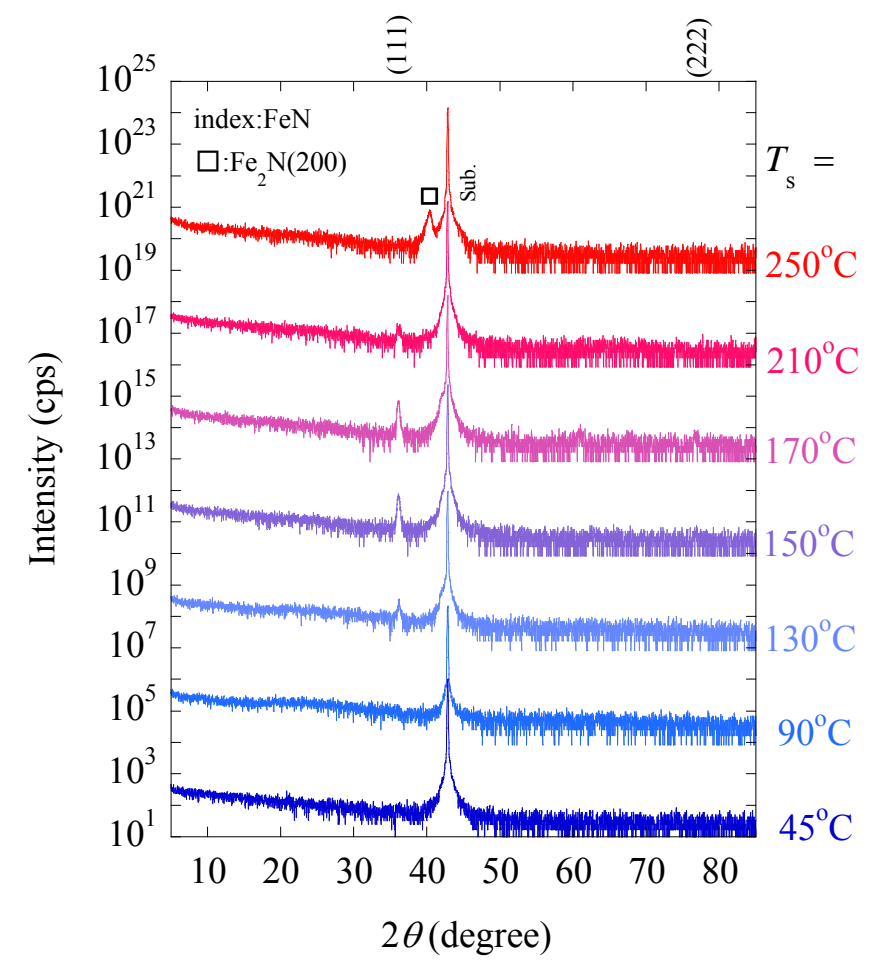

(b)

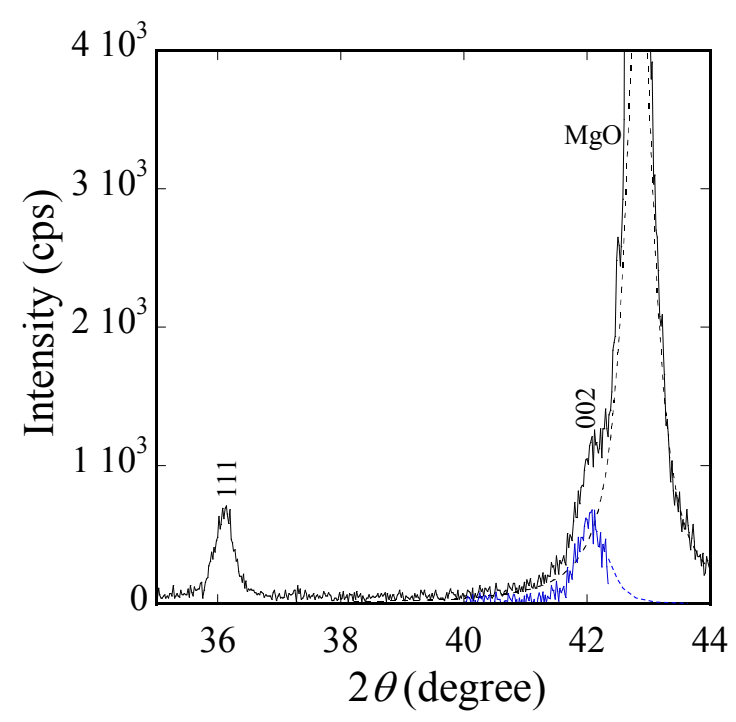

(c) 
Figure 2
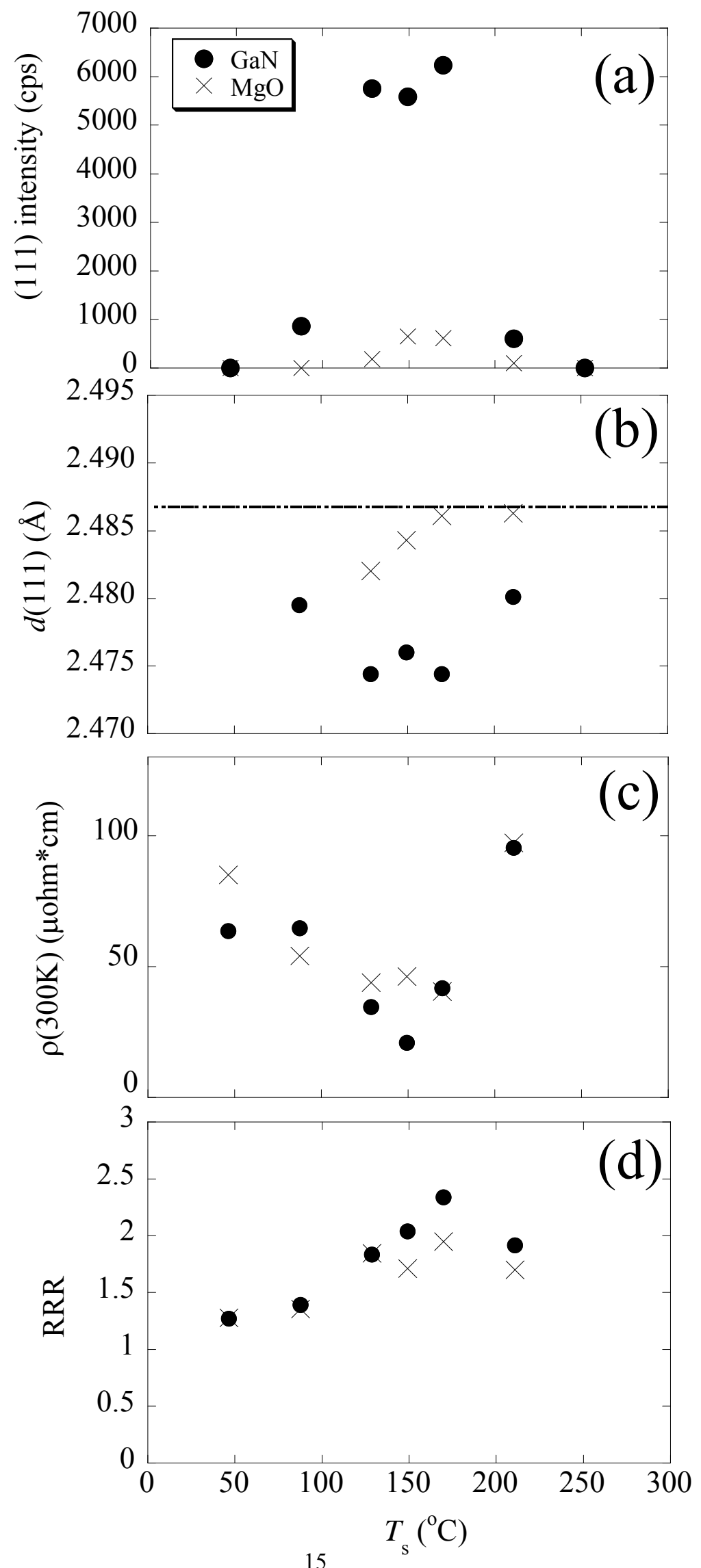
Figure 3

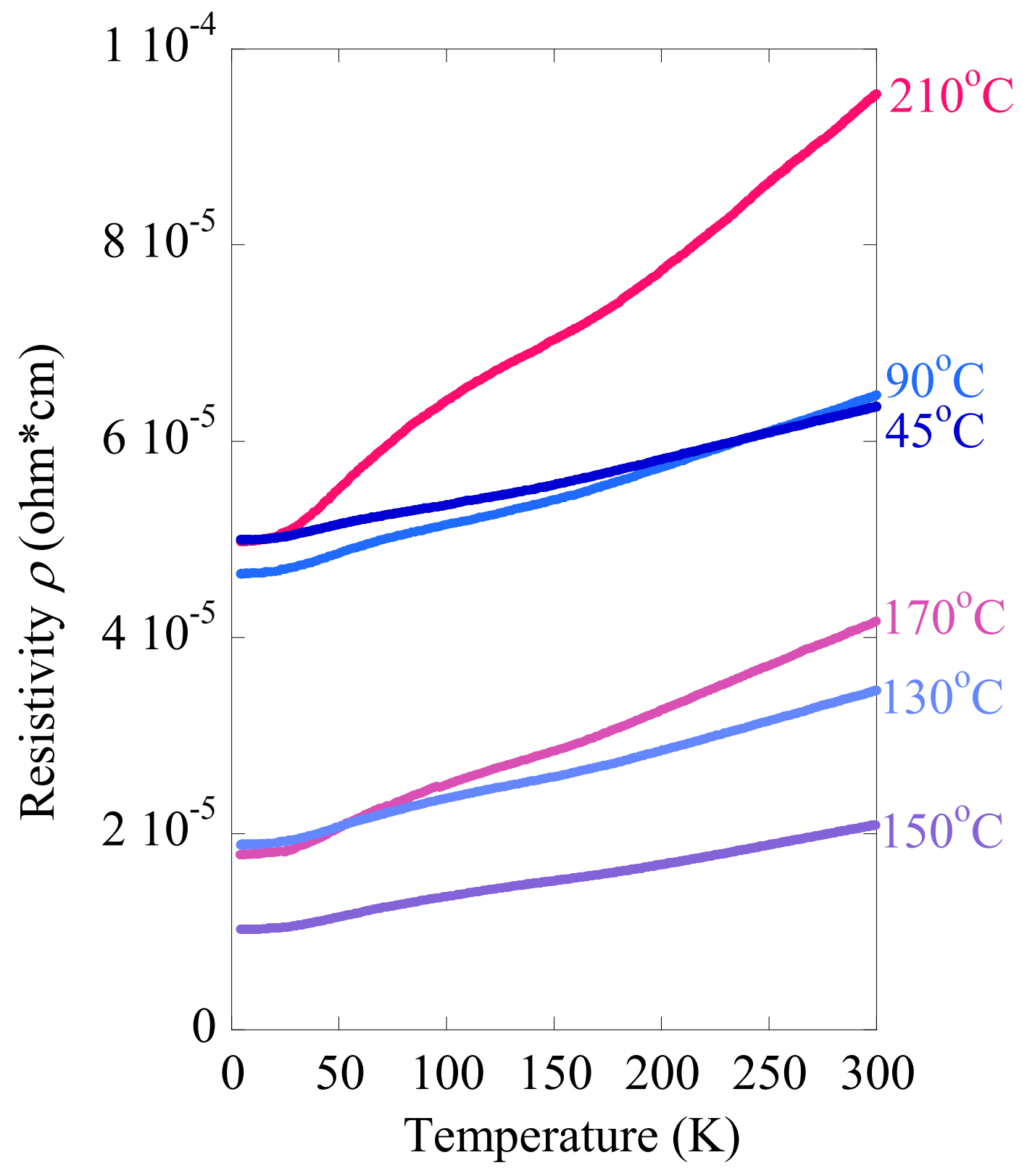


Figure 4

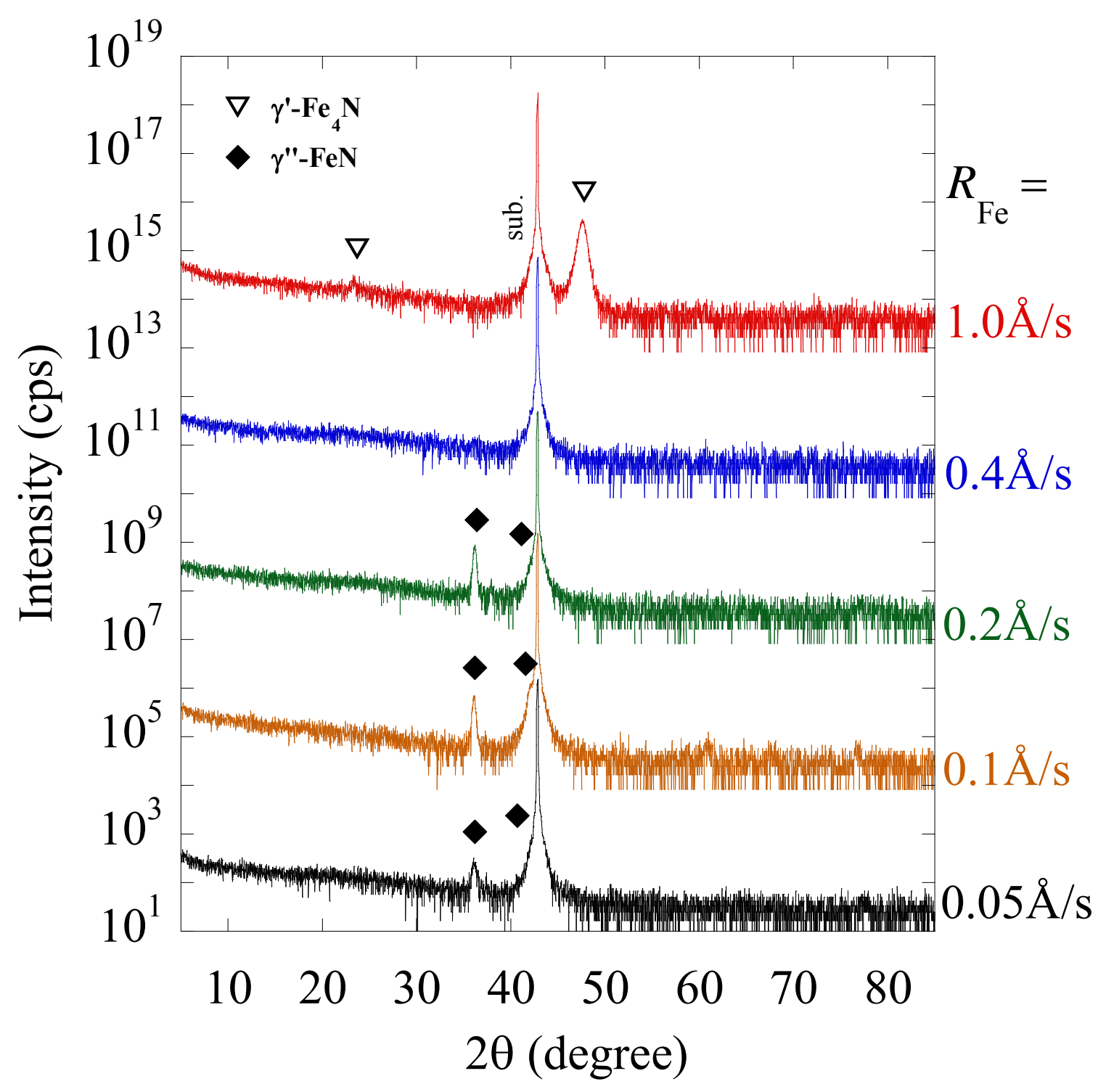


Figure 5(a), (b)

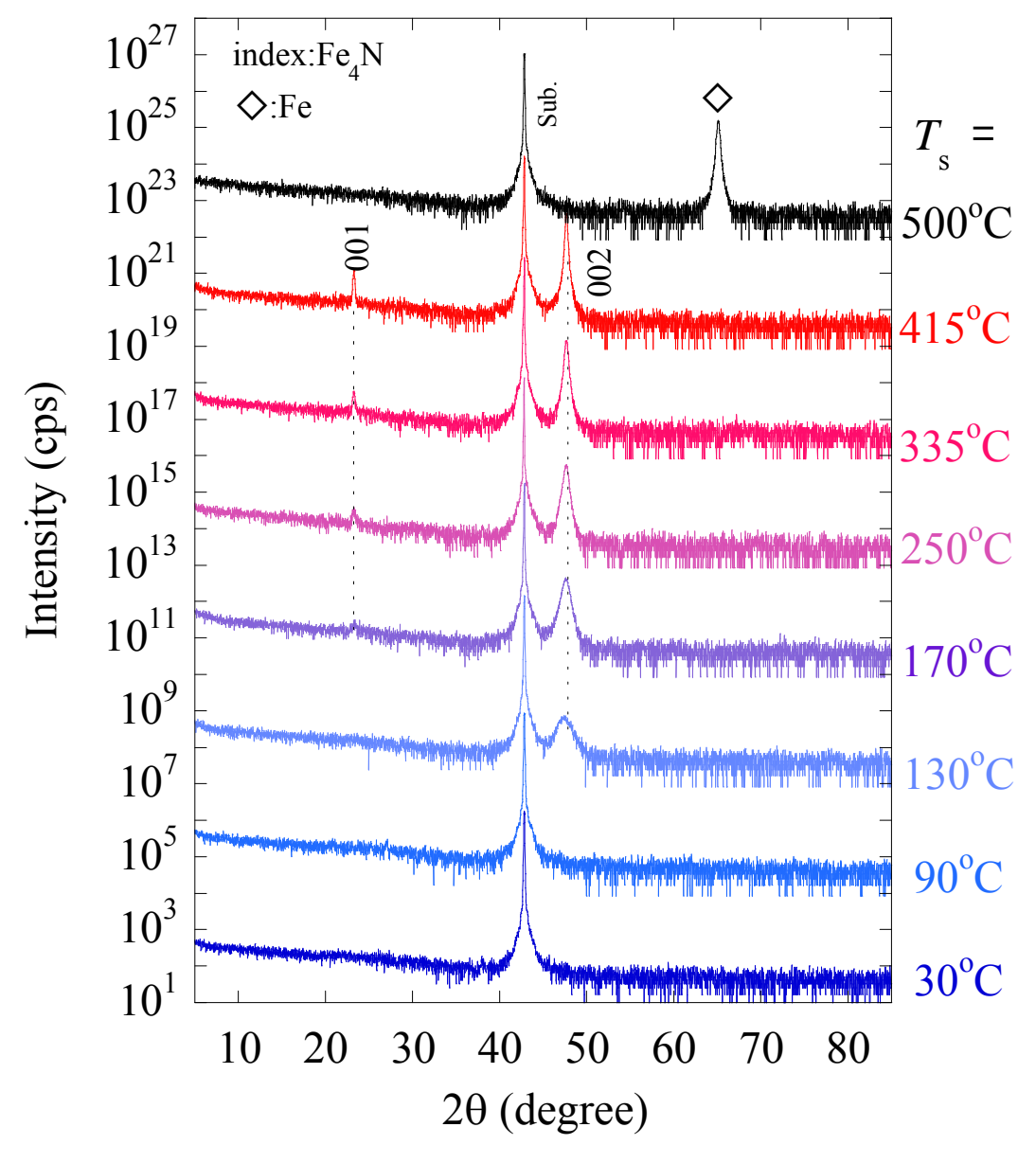

(a)

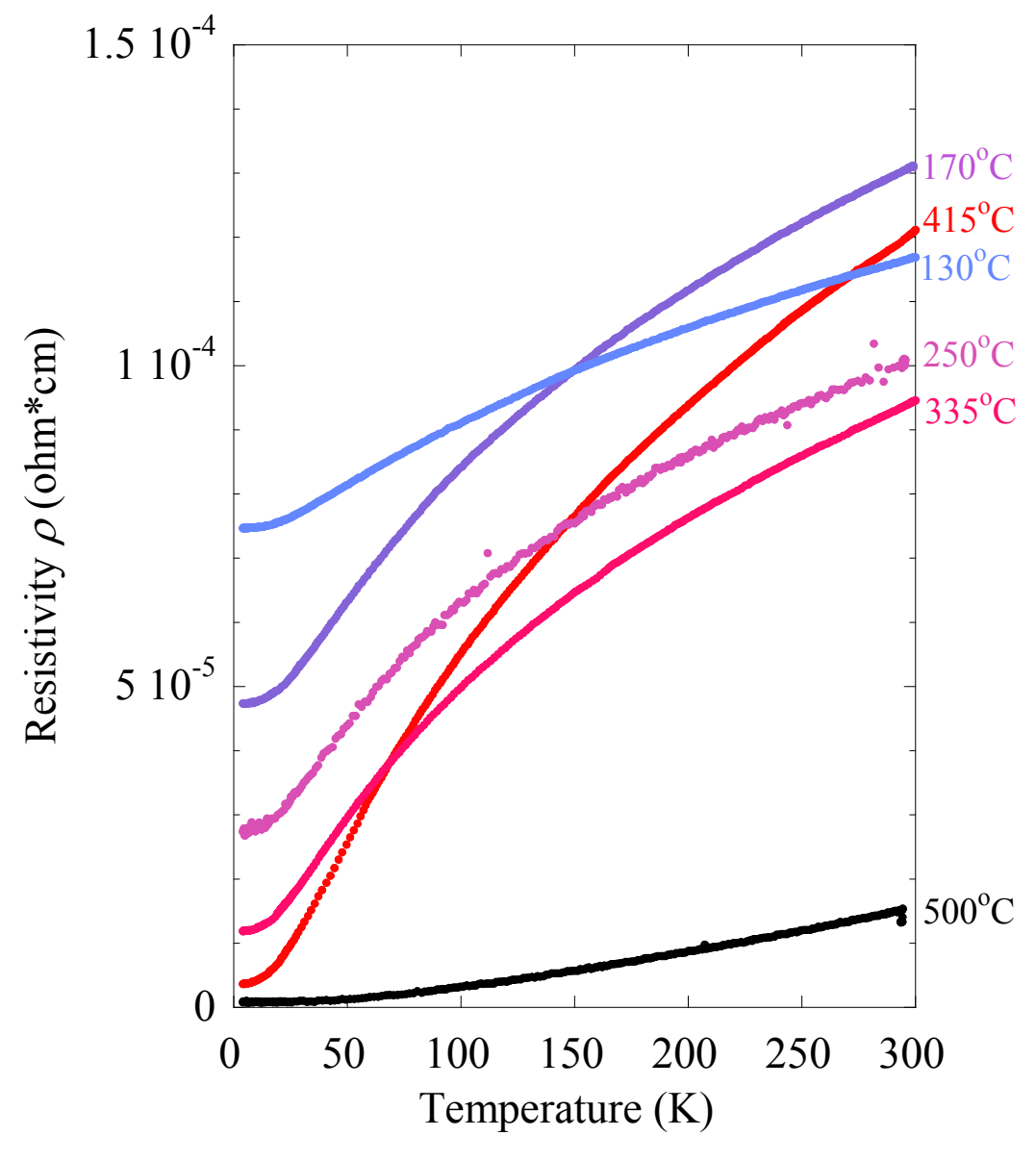

(b) 
Figure 5(c)
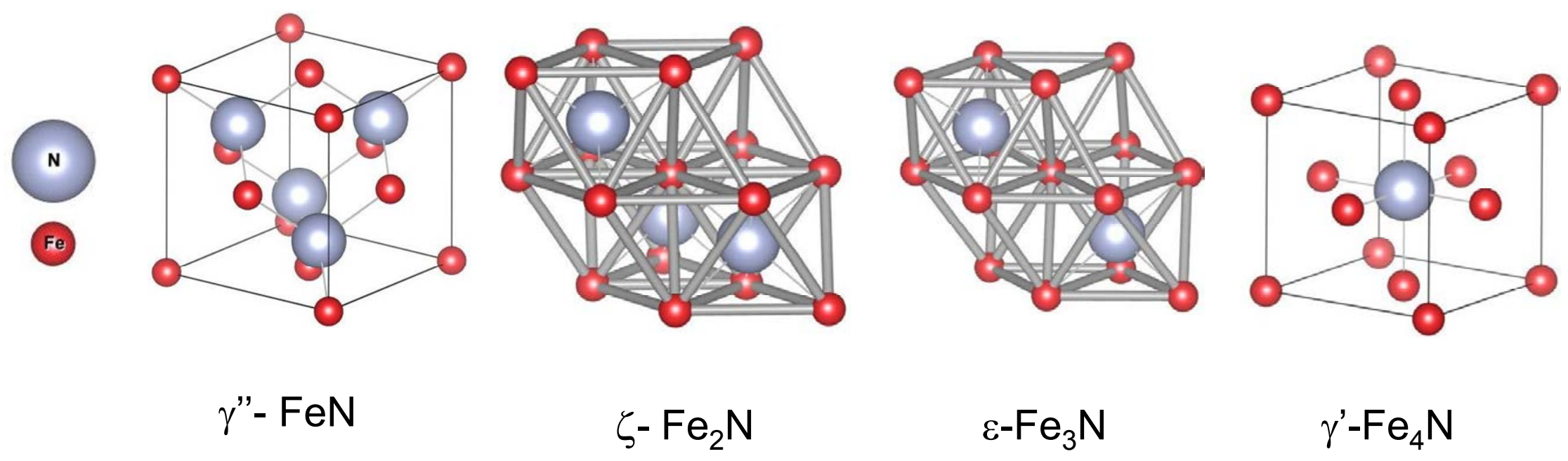
Figure 6
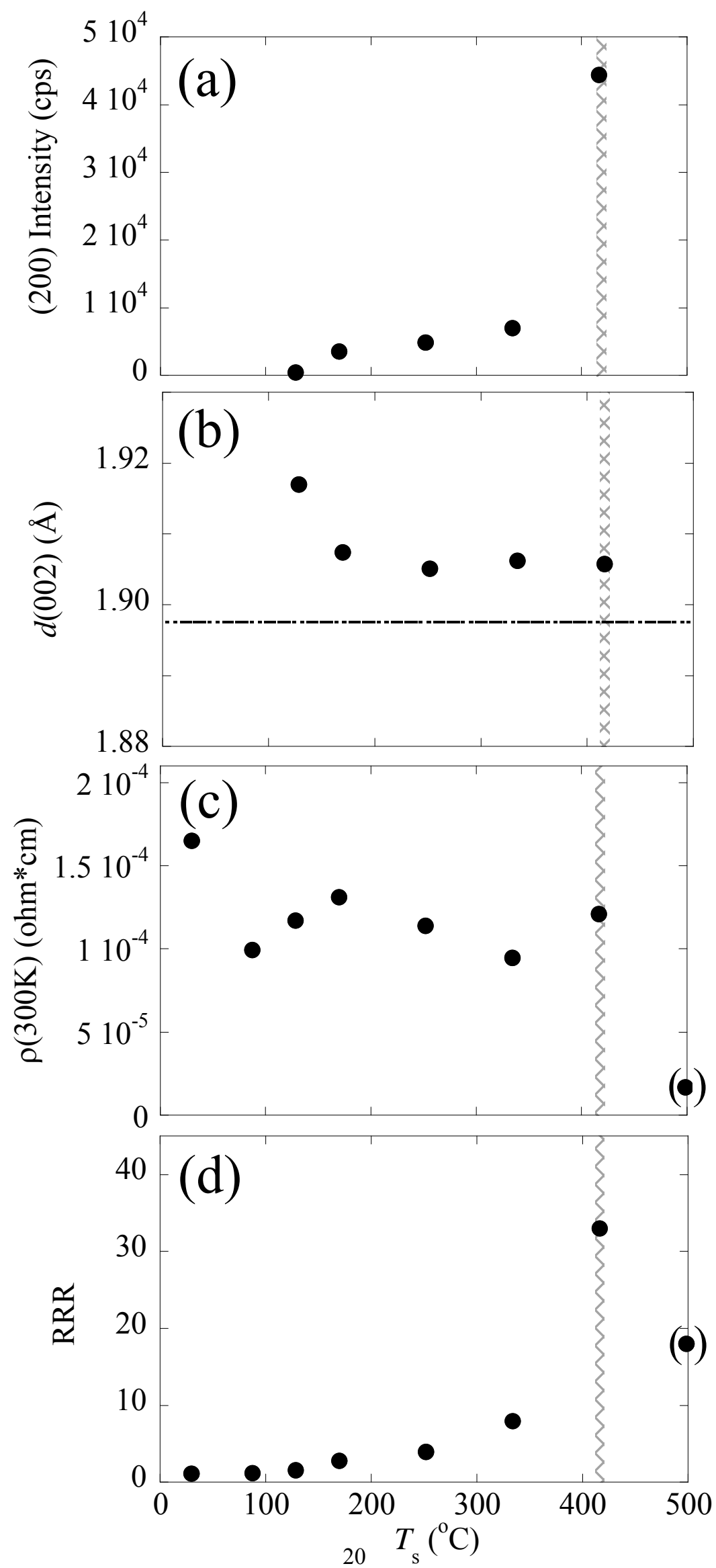